\title{
ANTIOXIDANT, CYTOTOXICITY, AND STABILITY EVALUATION OF GINKGO BILOBA EXTRACT-BASED MICROEMULSIONS FOR ENHANCED THERAPEUTIC ACTIVITY
}

\author{
MANISHA SINGH ${ }^{1}$, SURYA PRATAP SINGH ${ }^{2}$, RACHANA R $^{1 *}$
}

${ }^{1}$ Department of Biotechnology, Jaypee Institute of Information Technology, A-10, Sector 62, Noida - 201 307, Uttar Pradesh, India. ${ }^{2}$ Department of Biochemistry, Faculty of Science, Banaras Hindu University, Varanasi - 221 005, India. Email: Rachana.dr@gmail.com

Received: 10 May 2017, Revised and Accepted: 17 May 2017

\section{ABSTRACT}

Objective: This study is aimed to evaluate the antioxidant (AO) potential, cytotoxicity, and stability of preformulated Ginkgo biloba standard extract microemulsion (GBME), to investigate if, it retains the therapeutic potential of EGB761 and remains safe and stable for a longer period.

Method and Results: GBME has shown enhanced AO $\left(85.2 \pm 0.78 \%, \quad \mathrm{IC}_{50}=31.3 \pm 0.45 \mu \mathrm{g} / \mathrm{ml}\right.$ ) in comparison to EGB761 (74.1 $\pm 0.51 \%$, $\mathrm{IC}_{50}=49.4 \pm 0.05 \mu \mathrm{g} / \mathrm{ml}$ ) using 2,2'-azino-bis(3-ethylbenzothiazoline-6-sulphonic acid) (ABTS) assay. Similarly, 2,2-diphenyl-1-picryl-hydrazyl-hydrate $(\mathrm{DPPH})$ assay has also shown that AO for GBME $\left(94.6 \pm 0.04 \%, \mathrm{IC}_{50}=11.4 \pm 1.03 \mu \mathrm{g} / \mathrm{ml}\right)$ was higher than $\mathrm{EGB} \mathrm{G}\left(78.6 \pm 1.20 \%, \mathrm{IC}_{50}=34.6 \pm 0.81 \mu \mathrm{g} / \mathrm{ml}\right)$. Further, $\mathrm{IC}_{50}$ value of antiradical unit of GBME was much lesser (ABTS $=14.3 \pm 1.05 \mu \mathrm{g} / \mathrm{ml}$ and DPPH=17.03 $\pm 1.8 \mu \mathrm{g} / \mathrm{ml}$ ) in comparison to EGB761 (ABTS $=34.1 \pm 1.62 \mu \mathrm{g} / \mathrm{ml}$ and $\mathrm{DPPH}=37.5 \pm 0.08 \mu \mathrm{g} / \mathrm{ml}$ ). Equivalently, both, hydrogen peroxide scavenging activity, and nitric oxide activity were appreciably higher for GBME than the pure extract. The in vitro cytotoxicity assessment showed that GBME is quite safe (98.68 $\pm 0.76 \%$ cell viability) in comparison to EGB761 (83.29 $\pm 1.02 \%)$. Thereafter, these samples were tested for stability by evaluating their AO activity along with high-performance liquid chromatography analysis, for the major phytocompounds, after 1 year, and results suggested that AO of GBME remained stable while comparing with the freshly prepared GBME, whereas AO of EGB761 reduced significantly as compared to freshly taken EGB761 extract implying the degradation of phytocompounds supporting decrease in AO activity.

Conclusion: Therefore, the observed results suggest that GBME maintained AO and scavenging activity along with enhanced shelf life with no observed toxicity, which can be explored further for its potential therapeutic implications in various oxidative stress-induced central nervous system disorders.

Keywords: Phytoconstituents, Flavonoid, Nitric oxide, 2,2'-azino-bis(3-ethylbenzothiazoline-6-sulfonic acid) assay, radical scavenging activity, 3-[4,5-dimethylthiazol-2-yl]-2,5-diphenyl tetrazolium bromide assay.

(C) 2017 The Authors. Published by Innovare Academic Sciences Pvt Ltd. This is an open access article under the CC BY license (http://creativecommons. org/licenses/by/4. 0/) DOI: http://dx.doi.org/10.22159/ajpcr.2017.v10i8.19537

\section{INTRODUCTION}

Medicinal plants are the most opulent resource of bioactive compounds that have a wide application in various diseases. Around $80 \%$ of the world population is dependent on herbal medicines for their therapeutic benefits but on the contrary, very limited numbers of phytocompounds are approved by governing and regulatory authority's worldwide [1,2]. Treating central nervous system (CNS) ailments has been a challenging task due to various unavoidable physiological limitations [3]. There are various biological barriers such as blood brain barrier and bloodcerebrospinal fluid barrier which obstruct the drug distribution toward the targeted sites of brain thereby, prohibiting the passive diffusion of several compounds into the CNS [4]. One of the important pathological mechanisms leading to the various CNS disorders is generation of reactive oxygen species (ROS) [5]. Although the molecular form of oxygen is an essential component for the survival of living forms, its other forms such as superoxide ion can cause internal cell damage due to their oxidative properties [6]. Similarly, many biological and physiological processes in human body also cause production of ROS and free radicals as residual products. Many of these species are neutral but are unstable as they carry unpaired electrons and to attain stability; they pair themselves with other odd or unpaired electrons [7]. When these species are released in excess, they eventually cause oxidative stress, leading to structural and functional damage to essential biomolecules of body [8]. Therefore, these free radicals are reported to start the chain reactions, finally causing the diseased conditions due to initiation of apoptotic and other changes $[9,10]$. Various medicinal and herbal plants are being used as remedies to overcome such irregularities. Ginkgo biloba is reported to be a potential tree for the treatment and improvement of various neuronal disorders such as dementia, multiple sclerosis, Alzheimer's disease, tinnitus, and other cognitive impairments due to its polyvalent therapeutic actions [11]. It has been traditionally popular in China [12] and had also been extensively used as a nutraceutical and therapeutic drug compound in Europe and South Asian countries [13]. The standard extract of G. biloba (EGB761) is reported to have many important flavonoids such as quercetin-3- $\beta$-D-glucoside, quercitrin, rutin, quercetin, kaempferol, and isorhamnetin and terpene lactone components (ginkgolide A, B, C, bilobalide and Ginkgo toxin). It also includes 24\% flavone glycosides and $6 \%$ terpenes (ginkgolides A, B, C, and bilobalide) $[14,15]$.

The current research trends in pharmaceutical industries exhibit the preference of phytocompounds over the chemically fabricated drugs due to their comparatively higher patient compliance, with less side effects [16]. Standardized extract of $G$. biloba, has higher content of potential compounds such as flavonoids, polyphenols, and terpenoids, but these compounds are not very stable and get degraded easily in gut and other tissue fluids and also have shorter shelf life [17]. There are various other factors which lead to their low bioavailability, bioefficacy, permeability, and poor stability [18]. Therefore, more effective and stable delivery system is required to enhance their therapeutic index. Microemulsions (ME) are a viable system to eliminate the degradation hydrolysis and oxidation of the phytocompounds [19]. Hence, this study is primarily focused on comparing the antioxidant (AO) along with stability and cytotoxicity assessment of previously formulated GBME with the pure EGB761 extract, to evaluate if the developed ME system could enhance the bioavailability, therapeutic index, stability with longer shelf life. 


\section{METHODS}

The standardized EGB761 was obtained from the Ranbaxy Research Laboratory, India, as a gift sample, potassium persulfate $\left(\mathrm{K}_{2} \mathrm{O}_{8} \mathrm{~S}_{2}\right)$, ascorbic acid (AA), phosphomolybdate reagent, gallic acid, sodium nitroprusside, Folin-Ciocalteu, aluminum chloride were procured from High Media Laboratories, Mumbai, Maharashtra, India, and all other chemicals used were of analytical grade.

\section{Preparation of GBME}

The EGB761 extract loaded oil in water (o/w) ME system was prepared by water titration method as published before [20]. Where, isopropyl myristate, tween 80 , and ethanol were selected as oil, surfactant, and cosurfactant phases, respectively, along with water as aqueous phase. In addition, the stabilization of prepared $\mathrm{ME}$ formulation is equally essential and it is usually balanced by $\mathrm{S}_{\text {mix }}$ (surfactants and cosurfactants) components present in the colloidal system which equilibrates the interfacial tension between the oil droplets and aqueous phases [21], within the generally regarded as safe (GRAS) limits, thus all the excipients used in the formulation followed the criteria. The optimized formulation after approving their thermodynamic stability was further characterized by particle size, polydispersity index, zeta potential, transmission electron microscopy, Fourier transform infrared, and rheological studies analysis were accompanied by in vitro permeability kinetics [20].

\section{In vitro studies - $\mathrm{AO}$ assays}

Radicalscavenging assays (2,2'-azino-bis(3-ethylbenzothiazoline6-sulfonic acid) [ABTS] and 2,2-diphenyl-1-picryl-hydrazylhydrate [DPPH])

The AO potential and antiradical unit (AU) activity of EGB761 and GBME were estimated by both ABTS and DPPH assays [22].

As discussed by Re et al. (1999) [23] in case of ABTS assay, which is based on the ability of test samples to scavenge the radical cations and inhibit the oxidation of ABTS. These radicals were produced in response to the reaction between ABTS $(7 \mathrm{mM})$ solution in water with potassium persulfate $\left(\mathrm{K}_{2} \mathrm{O}_{8} \mathrm{~S}_{2}\right)(2.45 \mathrm{mM})$. The reaction mixture $(500 \mu \mathrm{l}$ of ABTS added with equal amount of $\mathrm{K}_{2} \mathrm{O}_{8} \mathrm{~S}_{2}$ ) was left for $16 \mathrm{hrs}$ in the dark at $37^{\circ} \mathrm{C}$ and then diluted further with $27 \mathrm{ml}$ of distilled water. Consequently, the DPPH assay which is widely used for analyzing AO activity of plant extracts specifically was also performed [24]. In this assay, reduction in the rate of chemical reaction absorption spectra was reflected by change of deep violet color in solution to pale yellow, after adding DPPH solution [25].

After this, in $20 \mu$ l of test samples (EGB761 and GBME) (10-100 $\mu \mathrm{g} / \mathrm{ml})$, $980 \mu \mathrm{l}$ of ABTS/DPPH reagent was mixed and stirred continuously (120 seconds) and incubated again for 30 minutes. Then absorbance was taken at $734 \mathrm{~nm}$ and $520 \mathrm{~nm}$, respectively to estimate for scavenging effect of the same.

Furthermore, reduction in ABTS and DPPH free radicals due to the antiradical compounds (EGB761 and GBME) was estimated further at the above-mentioned wavelengths $[26,27]$. AA $(10-50 \mu \mathrm{g} / \mathrm{ml})$ was used as a standard and scavenging effect of test samples (\%) were calculated as [28]:

$$
\text { Scavenging effect }(\%)=\frac{\left(\mathrm{A}_{\mathrm{OC}}-\mathrm{A}_{\mathrm{OT}}\right)}{\mathrm{A}_{\mathrm{OC}}} \times 100
$$

Where, $A_{\text {ос }}$ and $A_{\text {от }}$ are the absorbance of control and test samples, respectively.

Whereas, amount of $\mathrm{AUs}\left(\mathrm{AU}_{734}\right.$ and $\left.\mathrm{AU}_{520}\right)$ present in the tests compounds were estimated as [29]:

$\mathrm{AU}_{734}=\left(\mathrm{A}_{\mathrm{R} 0}-\mathrm{A}_{\mathrm{R} 1}\right)-\left(\mathrm{AR}_{\mathrm{CO}}-\mathrm{AR}_{\mathrm{C} 1}\right)$
$\mathrm{AU}_{520}=\left(\mathrm{A}_{\mathrm{R} 0}-\mathrm{A}_{\mathrm{R} 1}\right)-\left(\mathrm{AR}_{\mathrm{C} 0}-\mathrm{AR}_{\mathrm{C} 1}\right)$

Where, $A_{R 0}$ is the absorbance recorded for the test samples at the onset of reaction ( 0 seconds), and $A_{R 1}$ is the readings of the same samples taken after incubation time ( 30 minutes) of the reaction. While $\mathrm{AR}_{\mathrm{co}}$ represents the absorbance shown by control sample at the beginning of reaction and $\mathrm{AR}_{\mathrm{C} 1}$ is the absorbance taken after 30 minutes of the same [30]. Now, since $\mathrm{AR}_{\mathrm{C0}}-\mathrm{AR}_{\mathrm{C} 1}$ was always invariably equivalent to 0 hence, above equation can be reduced down to the following:

$\mathrm{AU}_{734}=\left(\mathrm{A}_{\mathrm{R} 0}-\mathrm{A}_{\mathrm{R} 1}\right)$

$\mathrm{AU}_{520}=\left(\mathrm{A}_{\mathrm{R} 0}-\mathrm{A}_{\mathrm{R} 1}\right)$

The $\mathrm{IC}_{50}$ values of the experimental models were also assessed to find out, the concentration of test samples that has inhibited $50 \%$ of the free radicals [31].

\section{Hydrogen peroxide scavenging activity}

Hydrogen peroxide is comparatively a very mild oxidant, present in phagosomes but due to its oxidizing behavior, it inactivates few enzymes such as human myeloperoxidase (MPO) and protein tyrosine phosphatases [32] and may alter many amino acids of protein structure by cleaving the peptidic bond, hence causing biocatalysis in cellular structures [33]. Therefore, to reduce down the excessive accumulation and toxic effects of $\mathrm{H}_{2} \mathrm{O}_{2}$ many $\mathrm{AO}$ phytocompounds are considered to be effective. Similarly, in this experiment, the capacity of G. biloba (EGB761) extract and its ME (GBME) were analyzed to scavenge the hydrogen peroxide by the method of Keser et al. (2012) [34]. In each aliquot (0.1 ml) of the experimental solutions (EGB761 and GBME) which were taken in different concentrations $(10-100 \mu \mathrm{g} / \mathrm{ml}), 50 \mathrm{mM}$ phosphate buffer ( $\mathrm{pH} 7.4$ ) was added and final volume was made up to $0.4 \mathrm{ml}$. Further, to this $0.6 \mathrm{ml}$ of hydrogen peroxide solution was added and incubated for 10 minutes; finally, absorbance was recorded at $230 \mathrm{~nm}$ [35]. The hydrogen peroxide scavenging activity of both was calculated and compared by AA which was used as a reference compound, by using following equation:

$$
\mathrm{H}_{2} \mathrm{O}_{2} \text { activity }(\%)=\frac{(\text { Control absorbance }- \text { Sample absorbance })}{(\text { Control absorbance })} \times 100
$$

\section{Nitric oxide (NO) scavenging activity}

NO is an essential biomolecule which controls and regulates various physiological mechanisms in human body such as transduction and propagation of neural signaling, regularizing the systemic circulation, antimicrobial and anticancerous activities but, when it reacts with free radicals, it develops peroxy nitrite anion (ONOO-) [36]. Therefore, we aimed to estimate the NO radical quenching ability of standard Ginkgo biloba (EGB761) along with its microemulsions (GBME), taking AA as a standard by spectrophotometric quantification. For this, $0.5 \mathrm{ml}$ of $10 \mathrm{mM}$ sodium nitroprusside (dissolved in PBS, pH 7.2) was added in $1 \mathrm{ml}$ of test samples (EGB761 extract and GBME) taken at different concentrations $(10-100 \mu \mathrm{g} / \mathrm{ml})$ and incubated at $25^{\circ} \mathrm{C}$ for $3 \mathrm{hrs}$. After this $1 \mathrm{ml}$ of Griess reagent is added and the absorbance of purple colored chromophore coupled with naphthyl ethylenediamine dihydrochloride was recorded at $546 \mathrm{~nm}$ [37], this complex developed due to the diazotization of nitrite with sulphanilamide. Then, $\%$ of inhibition was calculated by below mentioned formula [38]:

$$
\% \text { inhibition }=\frac{\mathrm{I}_{0}-\mathrm{I}_{1}}{\mathrm{I}_{0}} \times 100
$$

Where, $\mathrm{I}_{0}=$ Absorbance of control and $\mathrm{I}_{1}=$ Absorbance of test samples.

All the experiments were performed in triplicates, and the results are expressed as an average of all the independent determinations. 
In vitro cytotoxicity studies: 3-[4,5-dimethylthiazol-2-yl]-2,5diphenyl tetrazolium bromide (MTT) assay

The cytotoxicity of GBME was assessed on Vero cell line through the MTT colorimetric assay [39]. The cells were maintained in DMEM medium supplemented with $100 \mathrm{IU} / \mathrm{ml}$ penicillin, $100 \mu \mathrm{g} / \mathrm{ml}$ streptomycin, and $10 \%$ fetal bovine serum in humidified atmosphere of $5 \% \mathrm{CO}_{2}$ at $37^{\circ} \mathrm{C}$ to get adhered. The cells were trypsinized and seeded in triplicates at the concentration of $5.0 \times 10^{5}$ cells $/ \mathrm{ml}$ in 96 well tissue culture plates. Thereafter, the cells were treated with different concentrations (10-100 $\mu \mathrm{g} / \mathrm{ml}$ ) of test samples (EGB761 and GBME) for 6 and $12 \mathrm{hrs}$ individually, in each well. Subsequent to the incubation $20 \mu \mathrm{l}$ of MTT solution $(5 \mathrm{mg} / \mathrm{ml})$ was added to the respective wells and incubated again for $4 \mathrm{hrs}$, the viable cells converted the yellow dye MTT to formazan crystals, which were dissolved in $200 \mu \mathrm{l}$ of dimethyl sulfoxide and the optical density was determined by microplate reader at $570 \mathrm{~nm}[40]$.

\section{Stability testing of GBME and EGB761 extract}

The stability of test samples was evaluated by the method reported by Basheer et al., 2013 [41]. In this assay, the stability of EGB761 and GBME in various concentrations $(10-100 \mu \mathrm{g} / \mathrm{ml})$ was tested, in terms of their AO activity (ABTS and DPPH radical scavenging) after storing them to room temperature $\left(37^{\circ} \mathrm{C}\right)$ for 1 year and then comparing it with the $\mathrm{AO}$ of the fresh samples. The optimized and final formulation encapsulating the EGB761 extract was analyzed and quantified by using reversed phase, high-performance liquid chromatography (HPLC) (Waters) method [42] to evaluate the stability of important AO components (Quercetin, Isorhamnetine, and Kaempferol) after storing them for 1 year. The chromatographic analysis was done on $\mathrm{C}_{18}$ column with detection at $370 \mathrm{~nm}$, and temperature was fixed at $35^{\circ} \mathrm{C}$. A stock solution $(10 \mathrm{mg} / \mathrm{ml}$, with respect to extract present) of GBME was prepared in mobile phase with subsequent dilutions $(2-10 \mathrm{mg} / \mathrm{ml})$. The isocratic mobile phase for HPLC was consisted of methanol and phosphoric acid (0.3\%) in equivalent ratio (50:50), which was degassed by passing through a $0.45 \mu \mathrm{m}$ Millipore filter and sonicated for 10 minutes and pumped at a flow rate of $1 \mathrm{ml} /$ minute $[43,44]$.

\section{RESULT AND DISCUSSIONS}

\section{Preparation of GBME}

The GBME formulation was developed earlier [20] (particle size of $259.8 \pm 6.3 \mathrm{~nm}$, PDI score of $0.186 \pm 0.092$ and zeta potential as $-9.87 \pm 2.23 \mathrm{mv}$ ) using isopropyl mystriate, tween 80 , and ethanol as, oil, surfactant, and cosurfactant phases, respectively. Surfactant and cosurfactant components are very important in ME formulation as they reduce down the interfacial tension between the 2 phases (oil and water) [45]. In the present study, tween 80 which is a nonionic, hydrophilic surfactant, composed of same polar heads but different lipophilic tails are reported to have highest solubilization capacity, lowest toxicity and irritability properties, aiding in enhancing the therapeutic efficiency of GBME along with short chain alkanol (ethanol), which is known for improving the ME formulation by affecting the interfacial energy, when it interacts with surfactant monolayers [46].

\section{Radical scavenging assays (ABTS and DPPH)}

The measurement of AO activity through ABTS assay for EGB761 extract and GBME showed the higher AO activity of GBME $(89.2 \pm 0.78 \%)$ in comparison to EGB761 $(74.1 \pm 0.51 \%)$ at the highest concentration $(100 \mu \mathrm{g} / \mathrm{ml})$ (Fig. 1a). Consequently, the $\mathrm{IC}_{50}$ value of GBME was also noted significantly lesser $(29.6 \pm 0.03 \mu \mathrm{g} / \mathrm{ml})$ than the EGB761 (47.1 $\pm 0.32 \mu \mathrm{g} / \mathrm{ml}$ ) (Fig. 1a). Similarly, in case of DPPH estimation, AO activity of GBME $(94.6 \pm 0.04 \%)$ was again recorded to be higher than EGB761 $(77.6 \pm 1.20 \%)$, and $\mathrm{IC}_{50}$ value for GBME was estimated to be distinctly lower $(12.8 \pm 0.55 \mu \mathrm{g} / \mathrm{ml})$ than EGB761 $(31.1 \pm 0.81 \mu \mathrm{g} / \mathrm{ml})$ hence, reflecting more effective activity of GBME at lower concentrations too (Fig. $1 \mathrm{~b}$ ). Their $\mathrm{IC}_{50}$ value during ABTS assay gives an insight that GBME with all its components has equally comparable $\mathrm{AO}$ as the standard ( $\mathrm{AA}$ ) alone. Initially, it was

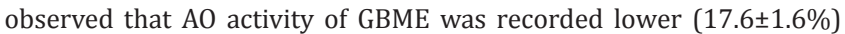

as compared to EGB761 $(22.61 \pm 0.82 \%)$ at $10 \mu \mathrm{g} / \mathrm{ml}$, as suggested by Koga et al., 2011 [47] this phenomenon may arise due to some of the phytocompounds getting partitioned into the oil phase and it took some time by them to partition out from the oil phase into the external medium. Later it was observed that, with the increase in concentrations, GBME exhibited fairly better activity than the extract. As, DPPH is highly sensitive toward even the weakest AOs and can very well analyze both hydrophilic and lipophilic components thus, in DPPH assay GBME, at its lowest concentration of $10 \mu \mathrm{g} / \mathrm{ml}$ also recorded higher (46.4 $\pm 1.6 \%) \mathrm{AO}$ activity than extract $(33.17 \pm 1.8 \%)$ as represented in Fig. $1 \mathrm{a}$ and $\mathrm{b}$. The reason for enhanced activity may be contributed by the components of the ME including extract as well as surfactant cosurfactants of the carrier system $(\mathrm{ABTS}=35.4 \pm 0.27 \%$ and $\mathrm{DPPH}=43.2 \pm 1.0 \%$ ).

Antiradical action of pure extract (EGB761), ME without extract and GBME in existence of ABTS as a source of radical enhancer (Table 1) was also compared with standard (AA). The $\mathrm{IC}_{50}$ values of all the test samples (AA, EGB761and GBME) were calculated and it was being observed that EGB761 showed the highest $\mathrm{IC}_{50}$ value $(34.6 \pm 0.81 \mu \mathrm{g} / \mathrm{ml})$, whereas IC $_{50}$ value of GBME $(12.8 \pm 0.55 \mu \mathrm{g} / \mathrm{ml})$ (Table 2) was slightly higher than the standard $(A A=11.2 \pm 0.26 \mu \mathrm{g} / \mathrm{ml}),(\mathrm{p}<0.5)$ suggesting the enhanced scavenging activity even at lower concentration.

\section{Hydrogen peroxide scavenging activity}

Hydrogen peroxide as mentioned above is known to be a weak oxidizing agent, and when it gets reacted with $\mathrm{Fe}^{2+}$ or $\mathrm{Cu}^{2+}$ complexes inside the cells, it forms highly reactive hydroxyl radicals which lead to its detrimental effects [46]. Hydrogen peroxide scavenging ability of both the test samples (EGB761 and GBME) was found to be dose dependent as it increases with the increase in concentrations of test samples (Fig. 2). IC $\mathrm{I}_{50}$ value for GBME and EGB761 were found to be $18.4 \pm 1.06 \mu \mathrm{g} / \mathrm{ml}$ and $42.8 \pm 0.45 \mu \mathrm{g} / \mathrm{ml}$, respectively, in comparison to

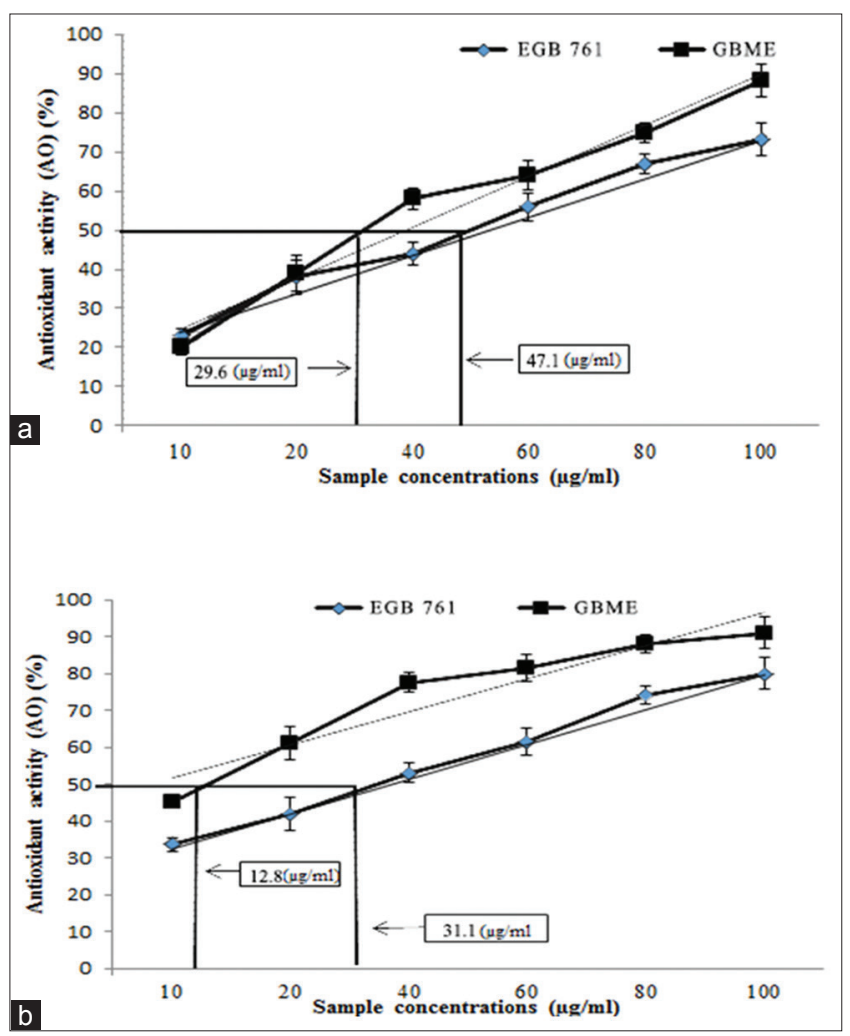

Fig. 1: (a) Antioxidant (AO) activity (\%) against 2,2'-azino-bis(3ethylbenzothiazoline-6-sulphonic acid) of EGB761 and GBME with $\mathrm{IC}_{50}$ values. (b) $\mathrm{AO}$ activity (\%) against 2,2-diphenyl-1picryl-hydrazyl-hydrate assay of EGB761 and GBME with IC values. EGB761: Purified standard extract of Gingko biloba, GBME: EGB761 loaded microemulsion 
Table 1: AU in ABTS and DPPH assay against EGB761 and GBME at various concentrations $(10-100 \mu \mathrm{g} / \mathrm{ml})$

\begin{tabular}{llllll}
\hline $\begin{array}{l}\text { Sample } \\
\text { conc. } \\
(\boldsymbol{\mu g} / \mathbf{m l})\end{array}$ & \multicolumn{2}{l}{ AU - ABTS method } & & \multicolumn{2}{l}{ AU - DPPH method } \\
\cline { 2 - 3 } \cline { 5 - 6 } & EGB761 & GBME & & EGB761 & GBME \\
\hline 10 & $0.141 \pm 0.02$ & $0.296 \pm 0.05$ & & $0.221 \pm 0.02$ & $0.395 \pm 0.006$ \\
20 & $0.238 \pm 0.01$ & $0.254 \pm 0.01$ & & $0.356 \pm 0.004$ & $0.570 \pm 0.09$ \\
40 & $0.318 \pm 0.07$ & $0.392 \pm 0.14$ & & $0.552 \pm 0.04$ & $0.583 \pm 0.15$ \\
60 & $0.546 \pm 0.09$ & $0.550 \pm 0.07$ & & $0.619 \pm 0.06$ & $0.834 \pm 0.11$ \\
80 & $0.567 \pm 0.11$ & $0.605 \pm 0.2$ & & $0.675 \pm 0.13$ & $0.846 \pm 0.08$ \\
100 & $0.612 \pm 0.17$ & $0.668 \pm 0.03$ & & $0.684 \pm 0.01$ & $0.945 \pm 0.07$ \\
\hline
\end{tabular}

AU: Antiradical unit, ABTS: 2,2'-azino-bis (3-ethylbenzothiazoline-6-sulfonic acid), DPPH: 2,2-diphenyl-1-picryl-hydrazyl-hydrate, EGB761: Extract of Gingko biloba, GBME: EGB761 loaded microemulsion

Table 2: IC $_{50}$ value of EGB761 and GBME against DPPH and ABTS assay

\begin{tabular}{llllll}
\hline AU & \multicolumn{2}{l}{$\begin{array}{l}\text { IC }_{50} \text { value of EGB761 } \\
(\mu \mathrm{g} / \mathrm{ml})\end{array}$} & & \multicolumn{2}{l}{$\begin{array}{l}\mathrm{IC}_{\mathbf{5 0}} \text { value of GBME } \\
(\boldsymbol{\mu g} / \mathbf{m l})\end{array}$} \\
\cline { 2 - 3 } \cline { 5 - 6 } & DPPH assay & ABTS assay & & DPPH assay & ABTS assay \\
\hline $31.1 \pm 0.81$ & $47.10 \pm 0.32$ & & $12.8 \pm 0.55$ & $29.6 \pm 0.03$ \\
\hline
\end{tabular}

AU: Antiradical unit, ABTS: 2,2'-azino-bis (3-ethylbenzothiazoline-6-sulfonic acid), DPPH: 2,2-diphenyl-1-picryl-hydrazyl-hydrate, EGB761: Extract of Gingko biloba, GBME: EGB761 loaded microemulsion

the standard $(\mathrm{AA})$ which was $12.5 \pm 0.83$, reflecting the fact that GBME has almost equivalent quenching ability as that of, standard and better than the pure extract. This improved characteristic of GBME can be attributed to the combination of the retained phenolic and flavonoid contents of extract along with the ME excipients [47]. Hence, from the results obtained, we can sequence the scavenging activity of hydrogen peroxide of various test samples as AA>GBME $>$ EGB761.

\section{NO scavenging activity}

The percentage inhibition of NO free radical was plotted against various concentrations $(10-100 \mu \mathrm{g} / \mathrm{ml})$ of test samples (EGB761 and GBME) as represented in Fig. 3. GBME showed $\%$ inhibition of $93.1 \pm 1.72 \%$ at its highest concentration of $100 \mu \mathrm{g} / \mathrm{ml}$, whereas the \% inhibition for standard (AA) was found to be $97.43 \pm 1.23 \%$ and EGB761=88.2 $\pm 1.6 \%$ on the same concentration. Furthermore, it can be concluded from the represented result data of dose-response curve that both of the test samples are concentration dependent. Hence, exhibiting the enhanced scavenging potential of GBME than EGB761 and ME without extract.

\section{In vitro cytotoxicity studies: MTT assay}

Cytotoxicity of mentioned test samples was tested on Vero cell line, using MTT assay. The results show (Fig. 4) that pure extract is more toxic $(63.14 \pm 0.72 \%$ cell viability) than GBME $(80.62 \pm 1.05 \%$ cell viability) at its highest concentrations $(100 \mu \mathrm{g} / \mathrm{ml})$. Results also showed a very low cytotoxic effect $(95.2 \pm 0.42 \%)$ of the ME system (only ME with no extract loading) indicating the nontoxic nature of the excipients used for the ME system (Fig. 5). These results were expected as the excipients selected for the formulation (ME) were within the GRAS limits. However, the label claim for the GBME is $60 \mu \mathrm{g} / \mathrm{ml}$, and till this range, no significant cellular toxicity was observed.

\section{Stability testing of GBME and EGB761 extract}

Stability of the test samples was checked after storing them at room temperature $\left(37^{\circ} \mathrm{C}\right)$ for 12 months and testing the retention ability of their AO content left after storing them for mentioned time by the same methods: ABTS and DPPH assay. It was being observed that EGB761 had shown a significance loss of AO in comparison to GBME ( $85.8 \pm 0.49 \%$ vs. $68.7 \pm 1.41 \% \mathrm{AO}$ activity) in case of ABTS assay. Similarly, through DPPH assay analysis also, EGB761 reflected a prominent loss and degradation of therapeutic phytocompounds with loss of AO activity of $65.2 \pm 1.06 \%$

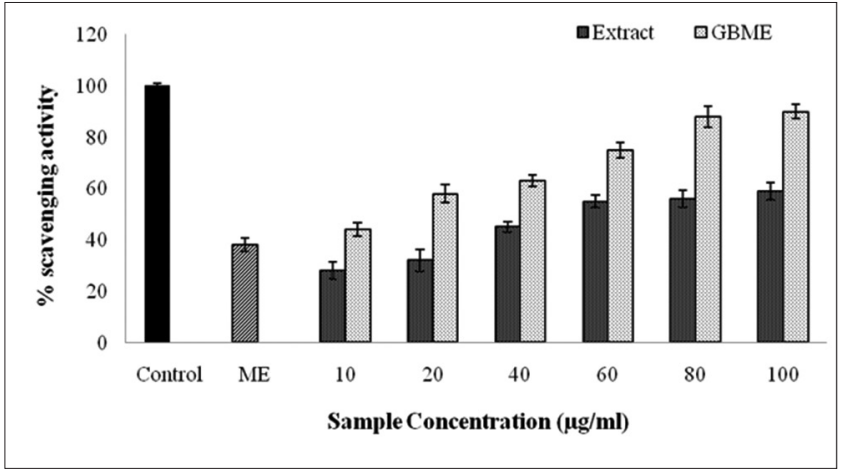

Fig. 2: Graph depicting $\mathrm{H}_{2} \mathrm{O}_{2}$ scavenging activity (\%) of ME, EGB761, and GBME at different concentrations. ME: Microemulsion without EGB761, GBME: EGB761 loaded microemulsion, EGB761: Extract of Gingko biloba

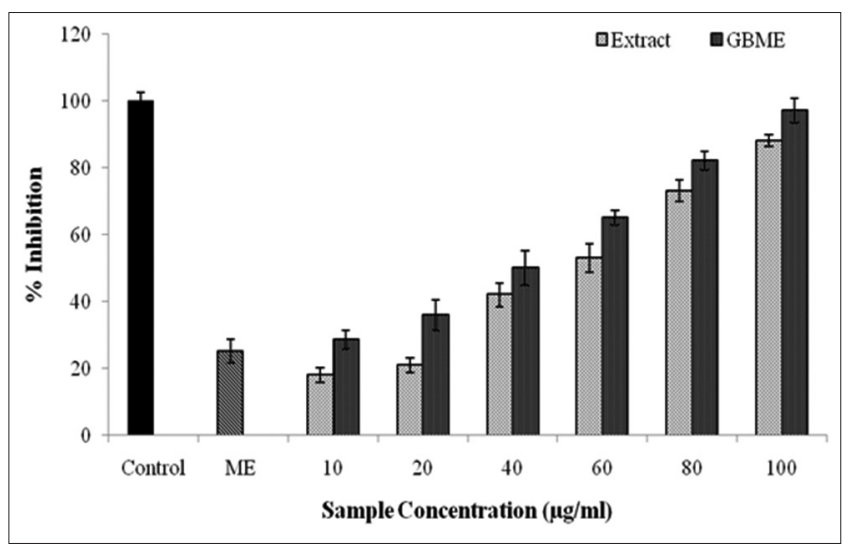

Fig. 3: Graph depicting nitric oxide scavenging activity (\%) of ME, EGB761 and GBME at different concentrations. ME: Microemulsion without EGB761, GBME: EGB761 loaded microemulsion, EGB761: Extract of Gingko biloba

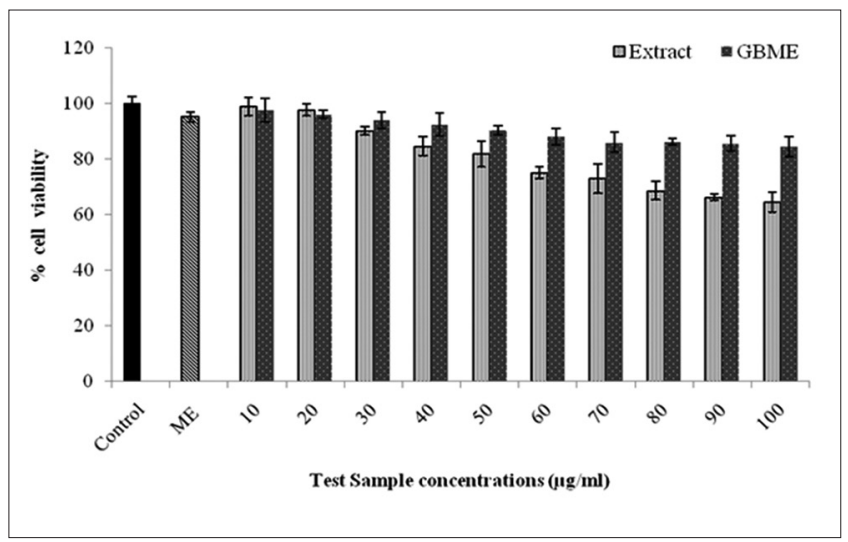

Fig. 4: In vitro cytotoxicity analysis of the optimized EGB761, ME and GBME at various concentrations $(10-100 \mu \mathrm{g} / \mathrm{ml})$ after 12 hrs of treatment by 3-[4,5-dimethylthiazol-2-yl]-2,5-diphenyl tetrazolium bromide assay. ME: Microemulsion without extract, GBME: EGB761 loaded microemulsion, EGB761: Purified extract of Gingko biloba

in comparison to GBME $(90.11 \pm 1.2 \%)$. As mentioned before the freshly prepared samples had higher AO of GBME (ABTS $=89.2 \pm 0.78 \%$ and $\mathrm{DPPH}=94.6 \pm 0.04 \%$ ) than EGB761 (ABTS $=74.1 \pm 0.51 \%$, $\mathrm{DPPH}=77.6 \pm 1.20 \%$ ). Therefore, from this comparative data, we can conclude that ME system has enhanced the stability and shelf life of the 
Table 3: Summarization of compound loss (\%) in flavonone group of GBME samples after the period of 12 months

\begin{tabular}{|c|c|c|c|c|}
\hline S.No. & Name of phyto compounds & Amount present before storage & Amount present after storage $(\mu \mathrm{g})$ & Calculated \% loss \\
\hline 1. & Quercetin & $0.54 \pm 0.002$ & $0.47 \pm 0.026$ & $12 \pm 0.001$ \\
\hline 2. & Kaempferol & $0.24 \pm 0.011$ & $0.21 \pm 0.005$ & $14 \pm 0.002$ \\
\hline 3. & Isorhamnetine & $0.12 \pm 0.084$ & $0.10 \pm 0.061$ & $16 \pm 0.01$ \\
\hline
\end{tabular}

GBME: Extract of Gingko biloba loaded microemulsion

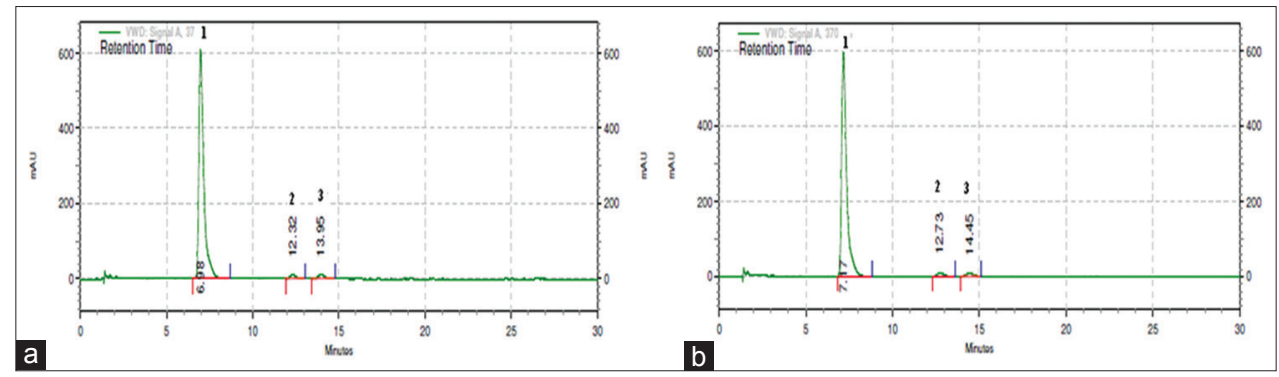

Fig. 5: (a) Representing high-performance liquid chromatography-ultraviolet (HPLC-UV) chromatogram of freshly prepared extract of Gingko biloba loaded microemulsion (GBME) samples, showing peaks of flavonone groups (quercetin, kaempferol, and isorhamnetine). The peak identified as: (1) quercetin, (2) kaempferol, and (3) isorhamnetine. (b) Representing HPLC-UV chromatogram of 12 months stored GBME samples, showing peaks of flavonone group (quercetin, kaempferol, and isorhamnetine). The peak identified as:

(1) quercetin, (2) kaempferol, and (3) isohamnetin

EGB761 extract significantly. Vicentini et al., 2011, have also shown that the ME system increases stability. Their formulation had quercetin in w/o ME with span80 (surfactant), tween 80 (cosurfactant) and canola oil as an external phase. Evaluation of AO of the formulation after 12 months indicated that the functional groups were retained. In this study, also the quantity assessment results of flavonone groups (quercetin, kaempferol, and isorhamnetin) present reflected that the GBME formulation was quite stable with no significant alteration in its therapeutically essential groups of phytocompounds as HPLC analysis of freshly made GBME showed concentration of $0.54 \pm 0.002 \mu \mathrm{g}, 0.24 \pm 0.011 \mu \mathrm{g}$, and $0.12 \pm 0.084 \mu \mathrm{g}$ (Fig. 5a) for quercetin, kaempferol, and isorhamnetine, respectively. Whereas, the stored samples (12 months) showed the retention of $0.47 \pm 0.026 \mu \mathrm{g}$ (quercetin), $0.21 \pm 0.005 \mu \mathrm{g}$ (kæmpferol), and $0.10 \pm 0.061 \mu \mathrm{g}$ (isorhamnetin) of the analyzed compounds, suggesting very negligible loss of the groups (Fig. $5 \mathrm{~b}$ ). Therefore, it can be concluded from the above results that the encapsulation of EGB761 extract in ME system has also enhanced its shelf life with respect to its important therapeutic compounds intact (Table 3).

\section{Statistical analysis}

The obtained result data were expressed by calculating mean of all experiments done in triplicates \pm standard error along with calculation of data significance at $\mathrm{p}<0.01$ by one-way ANOVA (50).

\section{CONCLUSION}

This study was conducted to evaluate if the developed formulation of EGB671 (G. biloba extract) could retain its therapeutic index with enhanced shelf life as the most effective therapeutic phytocompounds of EGB671 extract, flavone glycosides (quercetin, kaempferol, and isohamnetin) are reported to get degraded and metabolized in the gut, if taken orally in conventional form. G. biloba is a very important plant for treating nervous disorders, and there are many research groups working on to improve its therapeutic index and stability by various methods. We had developed a ME system earlier, and in this study, we have evaluated if we could achieve the aims as mentioned above. From this study, we can conclude that the $\mathrm{AO}$ and stability efficiency of EGB761 extract has enhanced after formulating it into ME system (GBME). Collectively, the experimental results suggested that the GBME formulation can effectively scavenge ROS and could provide effective protection against oxidative damage. The said ME were found to be equally efficient (in fact slightly more) in exhibiting their $\mathrm{AO}$ activity which might have been enhanced due to the already existing intrinsic activity of the carrier system components (ME). Furthermore, the major constituents of the extract were also found to be almost constant after 12 months storage at room temperature. Besides this, the amount and ratios of excipients (oil, surfactants and cosurfactants) used for the formulation of ME are listed and are under the GRAS limits and that may be the reason that formulation was found to be quite safe with the toxicity studies. The stability and shelf life of the formulation was also augmented in comparison to the pure extract. Thus, the developed ME of EGB761 extract could serve as a potential and effective delivery system and further can be analyzed in vitro and in vivo for its therapeutic index and safety.

\section{REFERENCES7}

1. Hsieh CL, Lao L, Lin YW, Litscher G. Complementary and alternative medicine for the treatment of central nervous system disorders. Evid Based Complement Alternat Med 2014;2014:175152.

2. Avigan MI, Mozersky RP, Seeff LB. Scientific and regulatory perspectives in herbal and dietary supplement associated hepatotoxicity in the United States. Int J Mol Sci 2016;17(3):331.

3. Nieoullon A. Neurodegenerative diseases and neuroprotection: Current views and prospects. J Appl Biomed 2011;9(4):173-83.

4. Upadhyay RK. Drug delivery systems, CNS protection, and the blood brain barrier. Biomed Res Int 2014;2014:869269.

5. Hotel N, Rico P. Universidad Metropolitana (UMET). New Jersey: New Jersey Institute of Technology; 2006.

6. Uttara B, Singh AV, Zamboni P, Mahajan RT. Oxidative stress and neurodegenerative diseases: A review of upstream and downstream antioxidant therapeutic options. Curr Neuropharmacol 2009;7(1):65-74.

7. Birben E, Sahiner UM, Sackesen C, Erzurum S, Kalayci O. Oxidative stress and antioxidant defense. World Allergy Organ J 2012;5(1):9-19.

8. Zuo L, Hemmelgarn BT, Chuang CC, Best TM. The role of oxidative stress-induced epigenetic alterations in amyloid- $\beta$ production in Alzheimer's disease. Oxid Med Cell Longev 2015;2015:604658.

9. Sharma P, Jha AB, Dubey RS, Pessarakli M. Reactive oxygen species, oxidative damage, and antioxidative defense mechanism in plants under stressful conditions. J Bot 2012;2012:1-26.

10. Ray PD, Huang BW, Tsuji Y. Reactive oxygen species (ROS) homeostasis and redox regulation in cellular signaling. Cell Signal 2012;24(5):981-90.

11. Chan PC, Xia Q, Fu PP. Ginkgo biloba leave extract: Biological, medicinal, and toxicological effects. J Environ Sci Health C Environ Carcinog Ecotoxicol Rev 2007;25(3):211-44.

12. Drago F, Floriddia ML, Cro M, Giuffrida S. Pharmacokinetics and bioavailability of a Ginkgo biloba extract. J Ocul Pharmacol Ther 2002;18(2):197-202. 
13. Nikam PH, Kareparamban J, Jadhav A, Kadam V. Future trends in standardization of herbal drugs. J Appl Pharm Sci 2012;2(6):38-44.

14. Ude C, Schubert-Zsilavecz M, Wurglics M. Ginkgo biloba extracts: A review of the pharmacokinetics of the active ingredients. Clin Pharmacokinet 2013;52(9):727-49.

15. van Beek TA, Montoro P. Chemical analysis and quality control of Ginkgo biloba leaves, extracts, and phytopharmaceuticals. J Chromatogr A 2009;1216(11):2002-32.

16. Bilia AR, Isacchi $B$, Righeschi $C$, Guccione $C$, Bergonzi MC. Flavonoids loaded in nanocarriers: An opportunity to increase oral bioavailability and bioefficacy. J Food Nutr Sci 2014;2014:1212-27.

17. Singh M, Singh SP, Rachana R. Development, characterization and cytotoxicity evaluation of Gingko biloba extract (EGB761) loaded microemulsion for intra-nasal application. J Appl Pharm Sci 2017:7:24-34.

18. Sarkhejiya N, Nakum M, Patel V, Atara S, Desai T. Emerging trend of microemulsion in formulation and research. Int Bull Drug Res 2012;1(1):54-83.

19. Re R, Pellegrini N, Proteggente A, Pannala A, Yang M, Rice-Evans C. Antioxidant activity applying an improved ABTS radical cation decolorization assay. Free Radic Biol Med 1999;26(9-10):1231-7.

20. Tirzitis G, Bartosz G. Determination of antiradical and antioxidant activity: Basic principles and new insights. Acta Biochim Pol 2010;57(2):139-42.

21. Moon JK, Shibamoto T. Antioxidant assays for plant and food components. J Agric Food Chem 2009;57(5):1655-66

22. Hamed MM, Mohamed MA, Ahmed WS. Chemical constituents, in vitro antioxidant activity, oral acute toxicity and $\mathrm{LD}_{50}$ determination of Moringa oleifera leaves. Int J Pharm Pharm Sci 2017;9:240-7.

23. Emad A. Antiradical and antioxidant activities of different Spirulina platensis extracts against DPPH and ABTS radical assays. J Mar Biol Oceanogr 2013;2:1-14

24. Wojtasik S, Sroka Z, Zbikowska B, Drys A. The measurement of antiradical activity of some plant raw materials and extracts with use of TAU734 (total antiradical unit). Herba Pol 2011;57(4):16-24.

25. El Darra N, Tannous J, Mouncef PB, Palge J, Yaghi J, Vorobiev E, et al. A comparative study on antiradical and antimicrobial properties of red grapes extracts obtained from different Vitis vinifera varieties. J Food Nutr Sci 2012;3(1):1420.

26. Malakyan M, Vardevanyan L, Yeghiazaryan D, Badzhinyan S, Agababyan A, Gevorgyan G. Antioxidant and antiradical properties of new amino-acid derivatives of aminoalcohols. J Pharm Chem $2010 ; 44: 421-3$

27. Nimmi O, George P. Evaluation of the antioxidant potential of a newly developed polyherbal formulation for antiobesity. Int $\mathbf{J}$ Pharm Pharm Sci 2012;4(3):505-10.

28. Badgujar N, Mistry K, Patel J. V. negundo, L. camara and B. variegata plants leaf extract exhibit considerable in vitro antioxidant and anticancer activities. Int J Pharm Pharm Sci 2017;9(5):227-32.

29. Keser S, Celik S, Turkoglu S, Yilmaz O, Turkoglu I. Hydrogen peroxide radical scavenging and total antioxidant activity of hawthorn. Chem J 2012;2:9-12

30. Hazra B, Biswas S, Mandal N. Antioxidant and free radical scavenging activity of Spondias pinnata. BMC Complement Altern Med 2008;8:63.

31. Omoya F, Akharaiyi F. Mixture of honey and ginger extract for antibacterial assessment on some clinical isolates. Int J Pharm Biomed Res 2011;2(1):39-47.

32. Sreeramulu D, Reddy CV, Chauhan A, Balakrishna N, Raghunath M. Natural antioxidant activity of commonly consumed plant foods in India: Effect of domestic processing. Oxid Med Cell Longev 2013;2013:369479.

33. Cai H, Dikalov S, Griendling KK, Harrison DG. Detection of reactive oxygen species and nitric oxide in vascular cells and tissues: Comparison of sensitivity and specificity. Methods Mol Med 2007;139:293-311.

34. Chang CL, Lin CS, Lai GH. Phytochemical characteristics, free radical scavenging activities, and neuroprotection of five medicinal plant extracts. Evid Based Complement Alternat Med 2012;2012:984295.

35. Tsai PJ, Tsai TH, Yu CH, Ho SC. Evaluation of NO-suppressing activity of several Mediterranean culinary spices. Food Chem Toxicol 2007;45(3):440-7

36. Mosmann T. Rapid colorimetric assay for cellular growth and survival: Application to proliferation and cytotoxicity assays. J Immunol Methods 1983;65(1-2):55-63.

37. Basheer HS, Noordin MI, Ghareeb MM. Characterization of microemulsions prepared using isopropyl palmitate with various surfactants and cosurfactants. Trop J Pharm Res 2013;12(3):305-10.

38. Croom E, Pace R, Paletti A, Sardone N, Gray D. Single-laboratory validation for the determination of terpene lactones in Ginkgo biloba dietary supplement crude materials and finished products by highperformance liquid chromatography with evaporative light-scattering detection. J AOAC Int 2007;90(3):647-58.

39. Yao X, Shang E, Zhou G, Tang Y, Guo S, Su S, et al. Comparative characterization of total flavonol glycosides and terpene lactones at different ages, from different cultivation sources and genders of Ginkgo biloba leaves. Int J Mol Sci 2012;13(8):10305-15.

40. Zhang Q, Chen LJ, Ye HY, Gao L, Hou W, Tang M, et al. Isolation and purification of ginkgo flavonol glycosides from Ginkgo biloba leaves by high-speed counter-current chromatography. J Sep Sci 2007;30(13):2153-9.

41. Mandal S, Mandal SS. Research paper microemulsion drug delivery system: A platform for improving dissolution rate of poorly water soluble drug. Int J Pharm Sci Nanotechnol 2011;3(4):1214-9.

42. Syed HK, Peh KK. Identification of phases of various oil, surfactant/cosurfactants and water system by ternary phase diagram. Acta Pol Pharm 2014;71(2):301-9

43. Koga K, Nishimon Y, Ueta H, Matsuno K, Takada K. Utility of nanosized, water-in-oil emulsion as a sustained release formulation of glycyrrhizin. Biol Pharm Bull 2011;34(2):300-5.

44. Saumya $\mathrm{S}$, Basha $\mathrm{P}$. In vitro evaluation of free radical scavenging activities of Panax ginseng and Lagerstroemia speciosa: A comparative analysis. Int J Pharm Pharm Sci 2011;3:165-9.

45. Vicentini FT, Vaz MM, Fonseca YM, Bentley MV, Fonseca MJ. Characterization and stability study of a water-in-oil microemulsion incorporating quercetin. Drug Dev Ind Pharm 2011;37(1):47-55.

46. Plapied L, Duhem N, des Rieux A, Préat V. Fate of polymeric nanocarriers for oral drug delivery. Curr Opin Colloid Interface Sci 2011;16:228-37.

47. Hicks CR. Fundamental Concepts in the Design of Experiments. New York: Holt, Rinehart and Winston; 1964. 